\title{
PERBANDINGAN HASIL KONSTRUKSI TERHADAP HASIL SIMULASI DARI ISOKRONUS MAGNET SIKLOTRON DECY-13
}

\section{COMPARATION OF CONSTRUCTION AND SIMULATION RESULT FROM ISOCHRONUS OF CYCLOTRON MAGNET DECY-13}

\author{
Idrus Abdul Kudus, Taufik, Kurnia Wibowo, Fajar Sidik Permana \\ Pusat Sains dan Teknologi Akselerator, Jl. Babarsari Kotak Pos 6101, ykbb, Yogyakarta \\ e-mail: idrus.ak@batan.go.id
}

Diterima 21 Juni 2017, diterima dalam bentuk perbaikan 21 September 2017, disetujui 5 Oktober 2017

\begin{abstract}
ABSTRAK
PERBANDINGAN HASIL KONSTRUKSI TERHADAP HASIL SIMULASI DARI ISOKRONUS MAGNET SIKLOTRON DECY-13. Dalam siklotron, magnet merupakan komponen utama untuk menghasilkan lintasan partikel melingkar dan memfokuskan berkas partikel. Sebuah sistem magnet siklotron dengan kapasitas 13 $\mathrm{MeV}$ telah berhasil dibangun. Selanjutnya karakteristiknya dievaluasi dengan membandingkan nilai isokronus magnet yang dibangun terhadap hasil simulasi. Hasil simulasi telah menunjukkan medan manet yang dihasilkan memenuhi nilai isokronus. Proses karakterisasi dilakukan melalui tahapan komisioning dan pemetaan medan magnet (untuk mengukur distribusi medan magnet dari setiap hill magnet) digunakkan sensor Tesla Meter. Pengukuran distribusi medan magnet dengan area pengukuran 960 × $960 \mathrm{~mm}^{2}$ dengan interval jarak pengambilan data $5 \mathrm{~mm}$ membutuhkan waktu \pm 9 jam. Dengan menggunakan arus koil maksimum 133,4 A dan menggunakan 2 (dua) hall probe hasil mapping medan magnet menghasilkan kurva medan rerata di atas medan isokronus dengan rentang kesalahan 0,3\%. Akan tetapi, pada jari-jari kurang dari $8 \mathrm{~cm}$ medan rerata masih di bawah kurva isokronus. Oleh karena itu, perlu proses shimming dengan menambah ketebalan bump 0,5 mm pada area pusat dan mengurangi medan rerata pada jari-jari lebih dari 8 $\mathrm{cm}$ supaya mendekati kurva isokronus.
\end{abstract}

Kata kunci: isokronus, magnet siklotron, pemetaan medan magnet, desain dan konstruksi

\section{ABSTRACT}

COMPARATION OF CONSTRUCTION AND SIMULATION RESULT FROM ISOCHRONUS OF CYCLOTRON MAGNET DECY-13. In a cyclotron, magnet is a major component to generate a circular trajectories of the particles and to focus the particles beam. A magnet system for DECY-13 MeV has been successfully constructed. This magnet is then evaluated by comparing its isochronus values to the isochronus values from the simulation results. This evaluation was performed through comissioning of the magnet at maximum coil current of $133.4 \mathrm{~A}$ and then the magnetic fields of each of the magnetic hills were mapped (to measure magnetic field distribution) using Tesla Meter sensor. The magnetic field were measured at every $5 \mathrm{~mm}$ distance interval during 9 hours with area $960 \times 960 \mathrm{~mm}^{2}$. The results show that the isochronus values of this constructed magnet are, in average, higher than the isochronus values of the simulation results with error of approximately $0.03 \%$. However, in the magnet radius below the $8 \mathrm{~cm}$, the isochronus values are less than the isochronus values of the simulation results. Therefore, it is necessary to performed the shimming process by increasing the thickness of the magnet for $0.5 \mathrm{~mm}$ in the central of the magnet region and reduce the mean field on a radius of more than $8 \mathrm{~cm}$ in order to obtain the more exact isochronus values.

Keywords: isochronus, magnet cyclotron, mapping magnetic field, design and construction

\section{PENDAHULUAN}

De emanfaatan radioisotop terus meningkat setiap tahunnya dan banyak digunakan digunakan untuk industri, pertanian, dan kesehatan. Dalam dunia kesehatan, pertumbuhan kebutuhan terhadap aplikasi pemanfaatan radioisotop saat ini sangat pesat, khususnya untuk Positron Emission Tomography (PET). PET adalah instrumentasi medik berbasis radioisotop dengan teknik pencitraan diagnostik yang aman, efektif dan noninvasive [1]. Oleh karena itu, penelitian dan pengembangan terhadap siklotron untuk pemanfaatan PET terus dikembangkan di berbagai negara [2]. Pusat Sains dan Teknologi Akselerator (PSTA), BATAN, saat ini sedang mengembangkan siklotron proton dengan energi $13 \mathrm{MeV}$ yang diberi nama Development of Experimental 
Jurnal Iptek Nuklir Ganendra

Ganendra Journal of Nuclear Science and Technology

Vol. 20, No. 2, Juli 2017 : 83-90

Cyclotron in Yogyakarta - $13 \mathrm{MeV}$ (DECY-13). Siklotron untuk PET pada umumnya menghasilkan proton dengan rentang energi $9 \mathrm{MeV}$ s.d. $18 \mathrm{MeV}$, sehingga siklotron proton DECY-13 dapat digunakan dalam pembuatan radioisotop untuk dimanfaatkan pada aplikasi PET [1].

Dalam penelitian dan pengembangan terhadap teknologi siklotron sangat penting untuk memahami karakteristik medan magnet. Magnet merupakan salah satu komponen utama siklotron yang berfungsi untuk menghasilkan lintasan partikel melingkar dan memfokuskan berkas partikel [3]. Pada siklotron, frekuensi RF selalu konstan sehingga penambahan energi partikel harus diimbangi dengan penambahan medan magnet ke arah radial [1]. Dampak dari membesarnya medan magnet secara radial adalah terjadi penyebaran (defocusing) partikel ke arah aksial sehingga memungkinkan partikel bertumbukan dengan kutub magnet. Oleh karena itu, kutub magnet dibuat sektor-sektor secara azimut sehingga dapat menghasilkan pemfokusan aksial [3].

Desain magnet siklotron proton $13 \mathrm{MeV}$ telah dilakukan pada tahun 2012 dengan dimensi $960 \times 960 \mathrm{~mm}$ seperti yang ditunjukkan pada Gambar 1. Desain magnet siklotron ini menggunakan program simulasi 3 dimensi perangkat lunak Opera 3D dan modul Tosca. Hasil desain menunjukkan bahwa siklotron telah memenuhi kurva isokronus dan pemfokusan yang baik. Selain itu dengan menggunakan data medan magnet dan listrik hasil desain yang dibuat dapat mencapai energi $13 \mathrm{MeV}$ pada simulasi lintasan berkas partikel [4].

Berdasarkan desain magnet siklotron tersebut, konstruksi medan magnet telah dilakukan pada tahun 2013. Akan tetapi hasil konstruksi tersebut perlu divalidasi terhadap karakteristik hasil desain yaitu dengan membandingkan nilai isokronusnya. Validasi nilai isokronus dilakukan dengan membandingkan nilai medan magnet terhadap radiusnya antara nilai desain dengan nilai simulasi. Tujuan penelitian ini adalah untuk mengetahui nilai isokronus, apabila nilai terpenuhi maka karakteristik magnet tersebut mampu digunakan dalam siklotron. Metode validasi terhadap karakteristik medan magnet siklotron dengan cara membandingkan hasil pengukuran dengan hasil simulasi juga dilakukan pada siklotron di beberapa negara antara lain siklotron jenis CYCIAE 100 [5]; VINCY Siklotron [6]; dan CYCHU-10 [7].

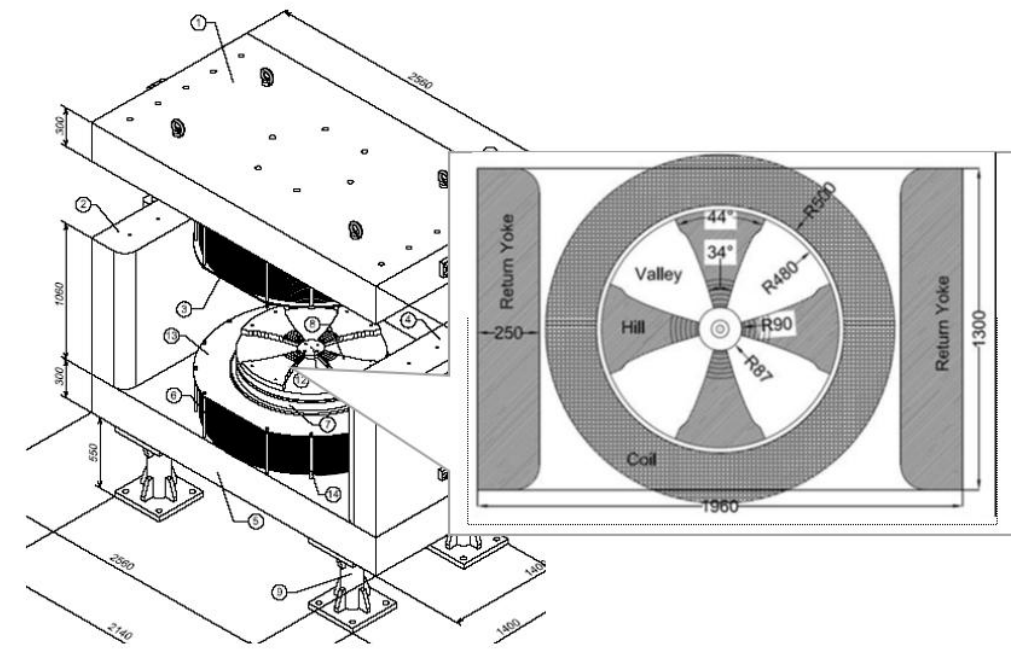

Gambar 1. Bentuk magnet DECY-13.

\section{METODOLOGI}

Metode yang dilakukan dalam penelitian ini ialah dengan mempersiapkan semua sistem pendukung meliputi sistem pendingin dan sumber daya magnet. Eksperimen pemetaan medan magnet siklotron dilakukan dengan mengambil data medan magnet dan selanjutnya dianalisis. Karakteristik magnet yang dirancang memiliki keunikan tersendiri karena harus dapat digunakan pada siklotron proton DECY-13. Spesifikasi magnet yang digunakan dalam konstruksi yang dimaksud dapat dilihat pada Tabel 1. Peralatan dan bahan yang diperlukan meliputi: sistem pendingin; magnet power supply; sensor Tesla Meter; alat pemetaan; komputer untuk penyimpan data; alat ukur suhu; dan flow meter.

Metodologi penelitian diawali dengan melakukan persiapan komponen yang diperlukan oleh magnet siklotron. Set up sarana pendukung operasional magnet dilakukan dengan melakukan komisioning terhadap 
magnet siklotron kemudian melakukan uji coba dengan tahapan seperti pada Gambar 2. Pengukuran distribusi medan magnet pada area bidang tengah kutub membutuhkan waktu selama 9 jam. Pengukuran dilakukan dengan 2 buah hall probe menggunakan sensor Tesla Meter dalam interval jarak pengambilan data $5 \mathrm{~mm}$. Tesla meter yang digunakan sudah terkalibrasi pada sertifikat pabrik dalam rentang presisi $\pm 0,01 \%$. Hasil yang didapat dari hasil pengukuran dianalisis untuk mendapatkan nilai perbandingan kurva isokronus antara hasil konstruksi dengan hasil simulasi. Kurva isokronus merupakan perbandingan nilai antara jari-jari magnet siklotron dengan nilai medan magnetnya [3].

Tabel 1. Spesifikasi rancangan magnet siklotron proton $13 \mathrm{MeV}$.

\begin{tabular}{|c|c|}
\hline Energi kinetik proton & $13 \mathrm{MeV}$ \\
\hline Jenis ion yang dipercepat & Ion $\mathrm{H}^{-}$ \\
\hline Tipe sumber ion & Internal \\
\hline Jumlah sektor magnet & 4 \\
\hline Celah valley & $120 \mathrm{~mm}$ \\
\hline Celah Hill & 40 s.d. $50,78 \mathrm{~mm}$ \\
\hline Frekuensi RF & $77,64 \mathrm{MHz}$ \\
\hline$B_{0}$ & $1.27479 \mathrm{~T}$ \\
\hline$B_{\text {hill }}$ maksimum & $1,942116 \mathrm{~T}$ \\
\hline$B_{\text {valley }}$ minimum & $0,7689 \mathrm{~T}$ \\
\hline Jumlah lilitan & $2 \times 304$ lilit \\
\hline Arus koil & $144,78 \mathrm{~A}$ \\
\hline Jari-jari kutub magnet $(R)$ & $0,48 \mathrm{~m}$ \\
\hline Sudut hill & $35^{\circ}$ s.d. $44^{\circ}$ dari pusat magnet \\
\hline Pergeseran fase & $\pm 13^{\circ}$ \\
\hline Dimensi magnet & $1,96 \mathrm{~m} \times 1,3 \mathrm{~m} \times 1,21 \mathrm{~m}$ \\
\hline Berat magnet (tanpa koil) & 17,3 ton \\
\hline $\begin{array}{c}\text { Set up } \\
\text { pendingin }\end{array}$ & $\begin{array}{c}\text { Komisioning } \\
\text { MPS }\end{array}$ \\
\hline $\begin{array}{c}\text { Grafik } \\
\text { isokronus }\end{array}$ & $\begin{array}{c}\text { Pemetaan } \\
\text { medan magnet }\end{array}$ \\
\hline
\end{tabular}

Gambar 2. Alur pengambilan nilai isokronus.

\section{SISTEM PENDINGIN}

Magnet power supply dan magnet siklotron membutuhkan sistem pendingin dengan menggunakan air. Sistem pendingin air yang diinstal terdiri dari menara pendingin dan chiller. Susunan sistem pendingin ditunjukkan pada Gambar 3. Menara pendingin berfungsi sebagai pendingin sekunder pada chiller dan untuk mengalirkan air dari tower pendingin ke chiller digunakan pompa pendorong. Chiller berfungsi sebagai pendingin primer yang digunakan secara langsung untuk mendinginkan magnet power supply dan magnet siklotron. Chiller mempunyai sistem penyedia air sendiri yang terpisah dari tangki penampung [8].

Berdasarkan hasil pengujian pada sistem pendingin, debit chiller saat dialirkan ke magnet siklotron sebesar 31,42 liter/menit. Rentang suhu yang dapat diatur pada chiller berada pada rentang $48^{\circ} \mathrm{F}-90^{\circ} \mathrm{F}$. Pada pengujian tanpa beban dengan pengaturan suhu $48^{\circ} \mathrm{F}$, suhu terendah hanya mencapai $48^{\circ} \mathrm{F}$. Akibatnya kompresor dan kontrol kapasitas terus aktif, sehingga lama kelamaan dapat mengakibatkan over current. Pada pengaturan suhu chiller $49^{\circ} \mathrm{F}$ tanpa beban, kompresor dan kontrol kapasitas mati pada suhu chiller $45^{\circ} \mathrm{F}$ dan aktif kembali setelah melampaui setting point $49^{\circ} \mathrm{F}$. Dengan demikian walaupun chiller dapat diatur sampai $48^{\circ} \mathrm{F}$, akan tetapi chiller bekerja dengan baik saat diatur $\geq 49^{\circ} \mathrm{F}$. 
Jurnal Iptek Nuklir Ganendra

Ganendra Journal of Nuclear Science and Technology

Vol. 20, No. 2, Juli 2017 : 83-90

Pengaturan suhu chiller yang rendah dapat mengakibatkan pengembunan pada beban maupun sepanjang saluran pendingin. Demikian pula sebaliknya untuk pengaturan suhu yang terlalu tinggi dapat mengakibatkan suhu air dari beban menjadi diatas ambang suhu maksimal. Pada magnet siklotron ini suhu air dari beban yang memasuki chiller dibatasi maksimal $86^{\circ} \mathrm{F}$. Dengan persyaratan di atas maka setelah diuji dengan beban arus magnet $138 \mathrm{~A}$, diperoleh pengaturan suhu chiller yang memenuhi syarat yaitu pada $73^{\circ} \mathrm{F}$. Pada pengaturan suhu chiller $73^{\circ} \mathrm{F}$ ini menghasilkan suhu air dari beban yang masuk ke chiller sebesar $82^{\circ} \mathrm{F}$ dan tidak mengalami pengembunan pada beban.

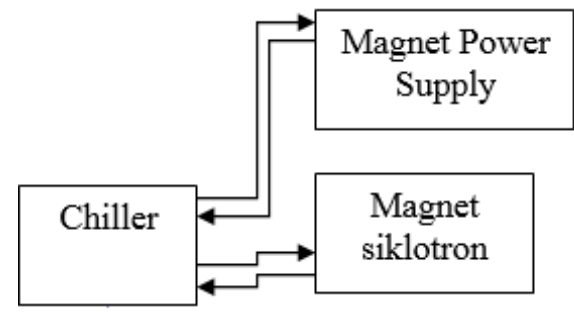

Gambar 3. Skema aliran system pendingin DECY-13.

\section{MAGNET POWER SUPPLY (MPS)}

Magnet siklotron didesain menggunakan elektromagnetik sehingga untuk membangkitkan magnet diperlukan arus listrik DC yang dilewatkan pada koil. Karena pada siklotron dibutuhkan kestabilan medan magnet yang tinggi, maka sumber arus koil harus memiliki tingkat kestabilan 100 part per millions (ppm). Oleh karena itu, untuk memperoleh sumber arus yang stabil digunakan MPS 855/System 8500 buatan Danfysik dengan spesifikasi ditunjukkan pada Tabel 2.

Tabel 2. Spesifikasi MPS855/System 8500 .

\begin{tabular}{ll}
\hline Stabilitas arus & $100 \mathrm{ppm}$ \\
\hline Arus output maksimum & $460 \mathrm{~A}$ \\
\hline Tegangan output maksimum & $100 \mathrm{~V}$ \\
\hline Polaritas & Unipolar \\
\hline Debit air pendingin & 8 liter/menit \\
\hline
\end{tabular}

Kinerja MPS di uji coba dengan mengalirkan arus pada magnet sebagai beban dan chiller sebagai pendinginnya. Hasil pengujian MPS dengan beban magnet memberikan hubungan antara arus yang dikeluarkan MPS dengan besar medan magnet yang dihasilkan (Gambar 4). Pengujian MPS dilakukan sampai 9 jam tanpa berhenti. Dari hasil pengujian tersebut, MPS dapat dioperasikan dengan baik sampai arus $138 \mathrm{~A}$ atau setara dengan 300000 ppm dengan tegangan output mencapai $75 \mathrm{~V}$.

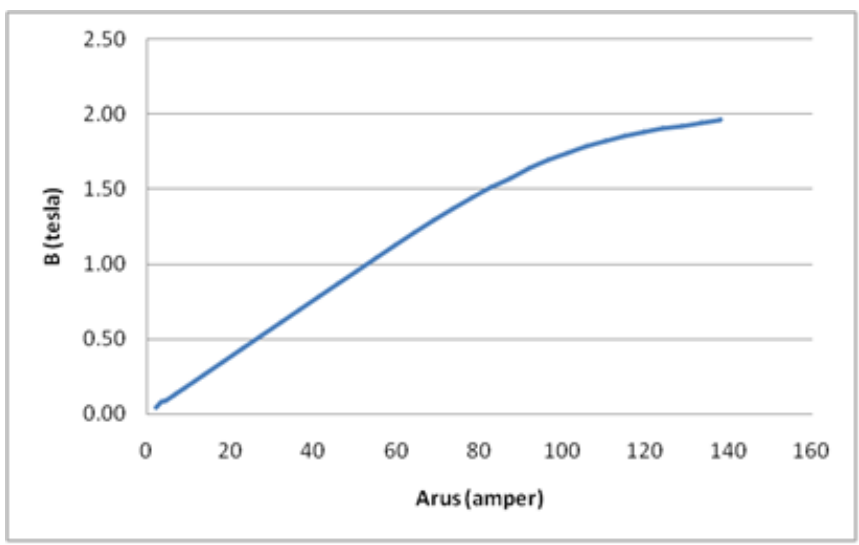

Gambar 4. Pengaruh arus koil terhadap medan magnet di hill 
Sesuai dengan desain, magnet siklotron harus dapat menghasilkan rapat fluks magnet di hill maksimal 1,95 T, oleh karena itu dilakukan penentuan karakteristik medan magnet pada hill terhadap arus koil. Berdasarkan hasil pengujian MPS untuk menghasilkan rapat fluks magnet di hill 1,95 T diperlukan arus sekitar $138 \mathrm{~A}$. Oleh karena itu pengoperasian magnet siklotron nantinya akan dioperasikan pada arus sekitar $138 \mathrm{~A}$.

\section{PEMETAAN MAGNET}

Data medan magnet diperoleh melalui pemetaan (mapping) medan magnet yang dilakukan dengan mengukur medan magnet arah tegak lurus bidang kutub magnet pada bidang tengah celah kutub magnet dalam koordinat kartesian $(\mathrm{x}, \mathrm{y})$ [3]. Pemetaan medan magnet dapat dilakukan pada interval posisi tertentu sesuai dengan yang diinginkan, akan tetapi interval yang terlalu besar menghasilkan akurasi data yang kurang baik, sementara interval data yang terlalu kecil mengakibatkan pemetaan menjadi lama [6]. Pemetaan medan magnet dilakukan dengan memetakan sensor Tesla meter sepanjang hill dan valley magnet siklotron dengan menggunakan alat mapping seperti yang ditunjukkan pada Gambar 5.

Berdasarkan hasil pengujian, diperoleh jarak interval posisi yang paling baik adalah $5 \mathrm{~mm}$ dengan waktu pemetaan yang diperlukan selama 9 jam. Sistem pemetaan medan magnet menggunakan 2 buah hall probe untuk memetakan seluruh sektor magnet (4 sektor) yang berukuran $960 \mathrm{~mm} \times 960 \mathrm{~mm}$. Dengan demikian hasil pemetaan seluruh sektor magnet dapat diperoleh dengan menggabungkan data medan magnet dari 2 hall probe tersebut [9].

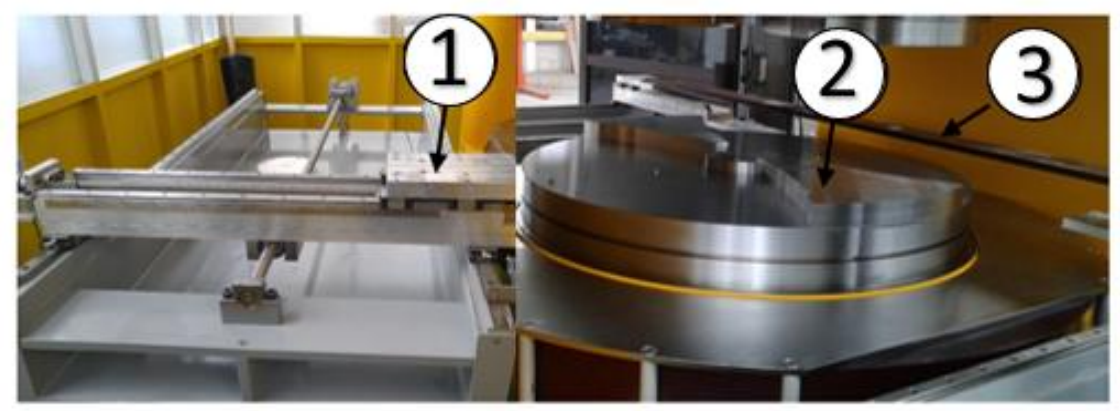

Gambar 5. Sistem pemetaan Siklotron: (1) alat pemetaan, (2) hill magnet, (3) posisi sensor.

\section{HASIL DAN PEMBAHASAN}

Pemetaan awal dilakukan dengan arus koil magnet $138 \mathrm{~A}$, akan tetapi hasilnya terlalu jauh dari medan isokronus pada medan magnet pusat (Bo) 1,2749 Tesla. Oleh karena itu arus koil diturunkan menjadi 133,4 A. Berdasarkan hasil desain kurva medan rerata harus mendekati kurva isokronus kecuali di daerah pusat medan rerata dibuat lebih tinggi dari medan isokronus seperti ditunjukkan pada Gambar 6.

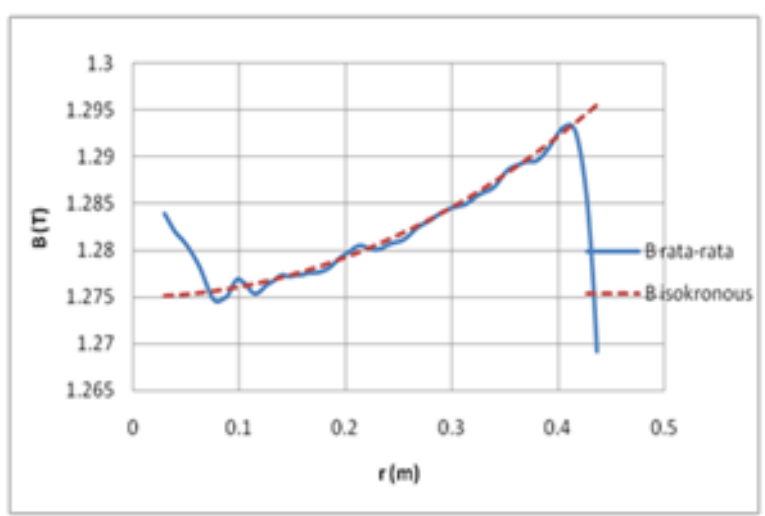

Gambar 6. Medan rerata hasil desain magnet siklotron (Taufik et al. 2014). 
Jurnal Iptek Nuklir Ganendra

Ganendra Journal of Nuclear Science and Technology

Vol. 20, No. 2, Juli 2017 : 83-90

Adapun hasil perhitungan medan rerata pemetaan awal dengan data seluruh sektor tidak dapat dilakukan. Hal ini disebabkan adanya perbedaan pengukuran medan magnet pada koordinat pertemuan kedua hall probe yang mengakibatkan lintasan kesetimbangan orbit partikel tidak terbentuk sehingga medan rerata tidak dapat dihitung. Sementara itu hasil pemetaan dari masing-masing hall probe dapat diperoleh seperti ditunjukkan pada Gambar 7. Hall probe pertama melakukan pemetaan bagian utara dan hall probe kedua melakukan pemetaan bagian selatan. Dari Gambar 7 tampak bahwa hasil pemetaan kedua probe menunjukkan medan rerata yang berbeda, akan tetapi mempunyai pola yang sama. Sebagai acuan shimming magnet bisa menggunakan salah satu hasil pemetaan dari hall probe, namun dalam hal ini digunakan hasil pemetaan probe yang utara.

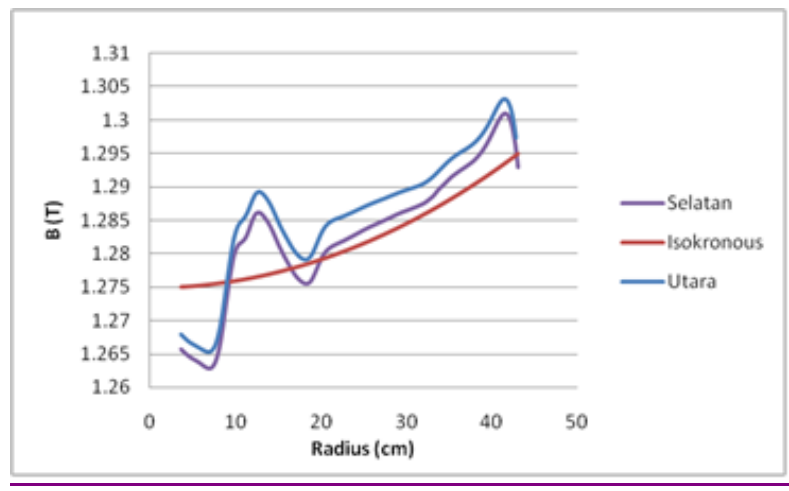

Gambar 7. Medan rerata hasil pemetaan magnet siklotron untuk masing-masing hall probe.

Pengambilan data menggunakan hasil probe utara karena medan magnet berada di atas kurva isokronus dengan rerata tingkat kesalahan $0,3 \%$ dengan rentang kesalahan $0 \%-1,1 \%$. Kecuali pada daerah kurang dari 8 $\mathrm{cm}$ medan magnet tidak mencapai nilai isokronus. Dari Gambar 8 terlihat perbandingan untuk pemetaan pertama kali medan magnet yang dihasilkan. Tingkat kesalahan tertinggi berada pada rentang $8-18 \mathrm{~cm}$ dengan maksimum kesalahan $1,1 \%$ terhadap nilai isokronus. Sedangkan pada titik radius $20 \mathrm{~cm}$ tingkat kesalahan mampu berada pada titik $0 \%$. Berbeda halnya dengan radius lebih dari $22 \mathrm{~cm}$ tingkat kesalahan $0,3 \%$. Tingkat kesalahan pada konstruksi magnet siklotron lainnya berada pada nilai $0,5 \%$ pada Compact Siklotron [10] dan 0,5\% pada CYCIAE Siklotron [5]. Hasil konstruksi medan magnet dapat disesuaikan mendekati nilai isokronus dengan hasil desain setelah proses shimming [7].

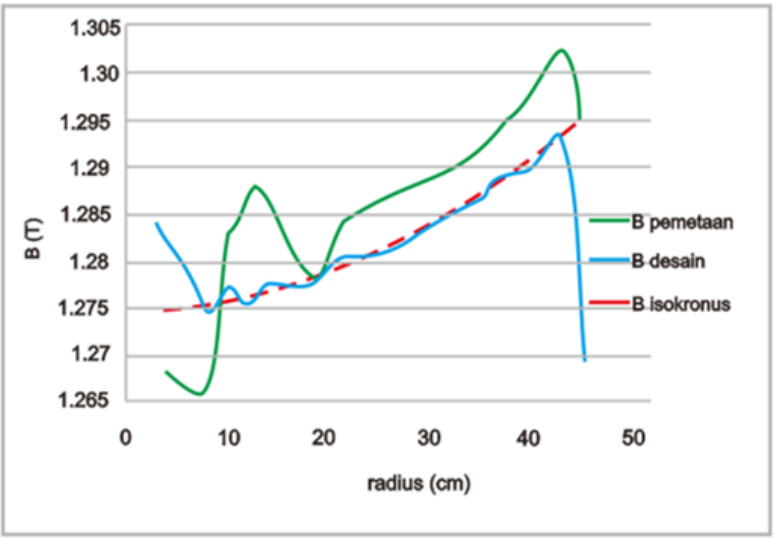

Gambar 8. Medan rerata hasil pemetaan dengan hasil desain dibandingkan dengan medan isokronus

Mengacu pada hasil desain, medan rerata pada radius kurang dari $8 \mathrm{~cm}$ harus lebih besar \pm 80 gauss dari medan isokronus. Oleh karena itu supaya medan pada daerah radius tersebut lebih besar, maka dilakukan pengurangan lebar celah dengan menambah ketebalan bump magnet $0,5 \mathrm{~mm}$. Penambahan ketebalan dilakukan dengan menambah bump pada masing-masing magnet $0,25 \mathrm{~mm}$. Hal ini juga dilakukan pada karakteristik magnet pada jenis sikotron lainnya; CYCIAE Siklotron $\pm 0,1 \mathrm{~mm}$ [5], VINCY Siklotron 0,2 - 0,3 mm [6]. Penentuan tambahan ketebalan bump magnet didasarkan pada hasil simulasi yang menunjukkan penambahan 
medan magnet 162 gauss. Setelah dilakukan perubahan ketebalan bump, medan rerata hasil modifikasi ditunjukkan pada Gambar 9.

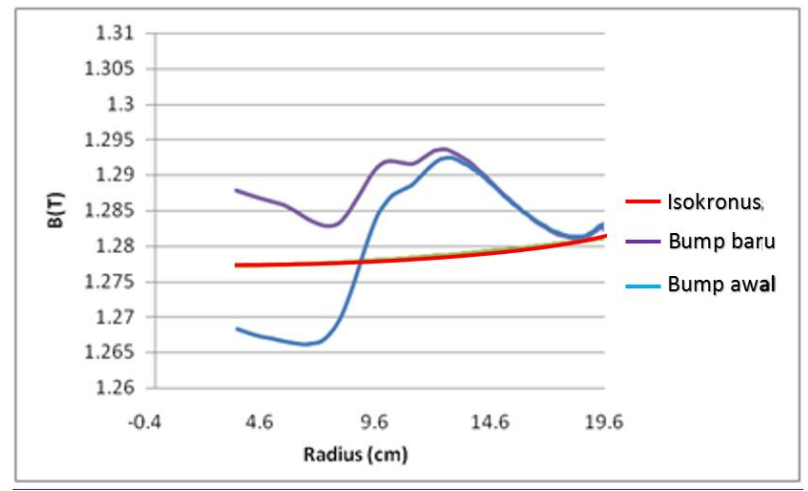

Gambar 9. Medan rerata setelah bump dimodifikasi pada daerah pusat.

Penambahan medan magnet setelah perubahan ketebalan bump 0,5 mm adalah 195 gauss dan menghasilkan selisih dengan medan isokronus sebesar \pm 100 gauss hasilnya tidak terlalu jauh dari hasil simulasi. Walaupun pada daerah pusat medan rerata sudah baik, akan tetapi pada jari-jari lebih besar dari $8 \mathrm{~cm}$ masih harus di shimming sehingga mendekati kurva isokronus [11].

\section{KESIMPULAN}

Berdasarkan hasil penelitian, pemetaan terhadap medan magnet hasil konstruksi dilakukan pada arus koil 133,4 A selama 9 jam. Hasil pemetaan medan magnet yang diperoleh dibandingkan terhadap nilai isokronus medan magnet hasil simulasi. Hasil perbandingan menunjukan kurva medan rerata magnet hasil konstruksi berada di atas medan isokronus hasil simulasi dengan rerata kesalahan 0,3\%, kecuali pada jari-jari kurang dari 8 $\mathrm{cm}$ medan rerata masih di bawah kurva isokronus. Pada jari-jari kurang dari $8 \mathrm{~cm}$ harus menambah ketebalan bump sebesar $0,5 \mathrm{~mm}$ untuk menghasilkan medan magnet yang lebih besar dari kurva isokronus. Pada jari-jari lebih dari $8 \mathrm{~cm}$ harus dilakukan proses shimming hill tip supaya mendekati kurva isokronus. Penambahan ketebalan bump dan proses shimming harus dilakukan agar fungsi magnet untuk menghasilkan lintasan partikel melingkar dan memfokuskan berkas partikel tercapai.

\section{UCAPAN TERIMA KASIH}

Penulis mengucapkan terima kasih atas bantuan dan kerjasamanya kepada Kepala Pusat yang telah menyediakan dana penelitian lewat DIPA PSTA dan kepada tim grup siklotron PSTA-BATAN serta pihak pihak yang telah menyumbangkan tenaga dan pikirannya pada kegiatan ini.

\section{DAFTAR PUSTAKA}

[1] Silakhuddin and S. Santosa, "Conceptual Design Study of $13 \mathrm{MeV}$ Proton Cyclotron," Atom Indones., vol. 38, no. 1, pp. 7-14, 2012.

[2] T. Zhang, Y. Lu, Z. Yin, J. Zhong, T. Cui, M. Li, S. Wei, G. Song, L. Wu, B. Ji, J. Xing, J. Qin, X. Jia, W. Hu, J. Yang, S. An, F. Guan, X. Zhen, L. Wen, J. Lin, Z. Li, X. Zhang, Y. Cai, and F. Yang, "Overall design of CYCIAE-14, a 14 MeV PET cyclotron," Nucl. Instruments Methods Phys. Res. Sect. B Beam Interact. with Mater. Atoms, vol. 269, no. 24, pp. 2950-2954, 2011.

[3] Taufik, A. Hermanto, P. Anggraita, and S. Santosa, "Determination of Magnet Specification of $13 \mathrm{MeV}$ Proton Cyclotron Based on Opera 3D," Atom Indones., vol. 40, no. 2, pp. 69-75, 2014.

[4] P. Anggraita, E. Mulyani, and I. A. Kudus, "Simulations of Beam Quality in a 13 MeV PET Cyclotron," Atom Indones., vol. 41, no. 3, pp. 145-149, 2015.

[5] T. Zhang, C. Chu, J. Zhong, J. Yang, J. Xing, Y. Lu, S. Wei, R. Chen, Z. Li, and M. Fan, "Magnet design and construction preparation for CYCIAE-100 at CIAE," Nucl. Instruments Methods Phys. Res. Sect. B Beam Interact. with Mater. Atoms, vol. 261, no. 1-2 SPEC. ISS., pp. 25-30, 2007.

[6] S. Ćirković, A. Ž. Ilić, A. Dobrosavljević, R. Balvanović, and J. L. Ristić-Djurović, "Minimization of the 
measurement errors induced by the cyclotron magnetic field measurement system," Nucl. Instruments Methods Phys. Res. Sect. A Accel. Spectrometers, Detect. Assoc. Equip., vol. 679, pp. 54-60, 2012.

[7] Z. H. Chen, D. Z. Chen, and B. Qin, "Magnetic Field Calculation and Magnet Shimming Simulation for Cychu-10 Cyclotron," Proc. Cyclotr. 2010, pp. 69-71, 2010.

[8] E. T. Budisantoso, Suprapto, and Sutadi, "Kinerja instalasi pendingin siklotron decy-13," Pros. Pertem. dan Present. IIm. Teknol. Akselerator dan Apl., vol. 17, pp. 50-55, 2015.

[9] K. H. Park, Y. G. Jung, D. E. Kim, B. K. Kang, M. Yoon, J. S. Chai, and Y. S. Kim, "Field mapping system for cyclotron magnet," Nucl. Instruments Methods Phys. Res. Sect. A Accel. Spectrometers, Detect. Assoc. Equip., vol. 545, no. 3, pp. 533-541, 2005.

[10] B. Qin, D. Z. Chen, L. C. Zhao, J. Yang, and M. W. Fan, "An improved matrix method for magnet shimming in compact cyclotrons", Nucl. Instruments Methods Phys. Res. Sect. A Accel. Spectrometers, Detect. Assoc. Equip., vol. 620, no. 2-3, pp. 121-127, 2010.

[11] D. Chen, K. Liu, J. Yang, Z. Chen, D. Li, B. Qin, J. Huang, Y. Q. Xiong, and M. Fan, "Fast and accurate magnetic field shimming for a compact cyclotron", IEEE Trans. Nucl. Sci., vol. 60, no. 3, pp. 2175-2179, 2013. 